some but contain a $Y$ chromosome with its associated nucleolus. Since products necessary for chromosome reduplication are already deposited in insect embryo cytoplasm $^{5,6}$ it may be that normal nucleolar function is also unnecessary during early embryogeny. In this respect, it is noteworthy that nucleoli usually do not develop during interphase of the rapid mitoses of early development. Hence, extreme caution should be exercised in interpreting nucleolar function from the particular case presented here. On the other hand, it is clear that at least 10-12 mitoses can occur in the Drosophila embryo when the zygote nucleus is devoid of a nucleolus.

R. C. von Borstel

M. L. REKEMEYER

Biology Division,

Oak Ridge National Laboratory*,

Oak Ridge, Tennessee.

March 31.

- Operated by Union Carbide Corporation for the U.S. Atomic Energy Commission.

1 McLeish, J., Heredity, 8, 385 (1954).

${ }_{2}$ Gaulden, M. E., and Perry, R. P., Proc. U.S. Nat. Acad. Sci. (in the pres.).

3 Lind

4 Poulson, D. F., J. Exp. Zool., 88, 271 (1940).

s von Borstel, R. C., in "The Beginnings of Embryonic Development", Bor vorstel, R. C., and Metz, C. B. (A.A.A.S., Washington, D.C., 1957).

6 Levenbook, I., Travaglini, E., and Schultz, J., Anat. Rec., 117, 585 (1953).

\section{A Mammalian Activity Rhythm independent of Temperature}

ONE of the most important characteristics of biological rhythms is their independence of temperature. Even the mammal may display a wide range of body temperatures, so that any hypothetical biochemical clock that it may possess may be 'challenged' to measure time at low temperatures. Some mammals have a wide range of body temperature both in a warm environment and while going into hibernation. Furthermore, with hypothermia as a procedure in human surgery, even human subjects undergo large changes in body temperature. Thus, measurements of rhythms in the cold mammal are of increasing interest. The following preliminary notes suggest the independence of temperature of a mammalian activity rhythm.

We have reported evidence for regularity in periodic awakening of ground squirrels from hibernation as follows: (1) hamsters and ground squirrels were maintained all summer at control temperatures with a daily cycle of $12 \mathrm{hr}$. of artificial light and $12 \mathrm{hr}$. of darkness ; (2) they were then permitted to hibernate for four months in a cold chamber $\left(6 \pm 1^{\circ} \mathrm{C}\right.$.) with a light cycle ( 7 foot-candles); (3) the awakenings of the hamsters were at random (50 per cent, at the time of the original light cycle), but the ground squirrels awoke 72 per cent of the time during the periods corresponding to the original light cycle ${ }^{1}$. New evidence is reported here, obtained from a second winter of observations on the same ground squirrels. The animals were illuminated in the cold room daily from 9 a.m. to 9 p.m. and only at these times were observations made. All eleven animals hibernated intermittently for four months, awakening after intervals of dormancy lasting from one to eighteen days ; 164 periods of dormancy were observed. Again for the second season more squirrels (63 per cent) awoke from the dormant condition when the light was on (results statistically significant). In most cases the squirrels went into hibernation in darkness (57 per cent). Interpretation must interrelate the following five points: (1) mammals in hibernation appear to be blind ${ }^{2}$, and once ground squirrels begin to awaken from hibernation they do not interrupt the process and return to the dormant condition until they have remained fully active for at least $12 \mathrm{hr} .{ }^{3}$; (2) ground squirrels have a distinct $24-\mathrm{hr}$. activity rhythm just before going into hibernation; (3) they are apt to enter into hibernation in dark periods (of minor importance in the present interpretation); (4) most individuals awaken from hibernation in illuminated periods; (5) they show variable periods of dormancy (1-18 days). This combination of observations can best be understood by postulating a clock, independent of temperature, controlling the state of the animal in hibernation. The best hypothesis seems to be that there are regular periods of shallow and deep hibernation, perhaps of about $12 \mathrm{hr}$. each. When either the light cycle or endogenous stimuli responsible for awakening (hunger, full bladder, etc.) coincide with the shallow phase, the animal may awaken. These interpretations are being tested experimentally.

The ecological significance of a clock independent of temperature in hibernation can be illustrated by the important rule that the rodent $24-\mathrm{hr}$. rhythm (which can be represented as a dial of behaviour sequences) can be reversed or 'turned' by $12 \mathrm{hr}$. only by a gradual process taking at least four days ${ }^{4}$. Thus, if a free ground squirrel, which is a day-active species, were to awaken at night from hibernation in the spring, it would probably be incapable of causing its behaviour sequence to jump the gap to the day period until several days had elapsed. Apparently this could be avoided by the independence of tem. perature of the biological clock during hibernation.

This research was aided by a grant from the National Scientific Foundation, Washington, D.C.

G. Edgar Folk, JUN.

Mona R. Meltzer

Richard E. GrindelaAND

Department of Physiology,

State University of Iowa, Iowa City. April 17.

${ }^{1}$ Folk, jun., G. E., Amer. Nat., xci, 153 (1957).

2 Lyman, C. P., and Chstfield, P. O., Physiol. Rev., 35, 403 (1955).

${ }^{3}$ Dawe, A. R., and Morrison, P. R., Amer. Heart J., 49, 367 (1955).

4 Folk, jun., G. E., Proc. Fifth Conf. Biol. Rhythms, Stockholm (1955).

\section{Diego as an Independent Blood-Group System}

IT has been repeatedly found that a blood-group antigen thought to be a part of a 'new' blood-group system is in fact part of an old one; $\mathrm{Tj}^{\mathrm{a}}$ is now part of the $P$ system; U, $\mathrm{V}^{\mathrm{w}}$ and $\mathrm{Mi}^{\mathrm{a}}$ of the MNSs system. Concerning the more recently reported 'new' antigen Dia, publications up to, and including, that of Levine and Robinson ${ }^{1}$ have shown its inheritance to be independent of the genes of the $A B O, M N S s, P, R h$, Lewis and Kidd systems, and that it is not identical with any of six previously described antigens of low frequency, Ven, $\mathrm{Ca}, \mathrm{Be}^{\mathrm{a}}, \mathrm{Wr}^{\mathrm{a}}, \mathrm{By}^{\mathrm{a}}$ and $\mathrm{Rm}$. That it is not part of the Duffy or Kell system has not been proved.

As part of a study of blood-group genes of a Japanese population in Canada, we recently published ${ }^{2}$ the blood groups, so far as we were able to carry 